\title{
CLINICOPATHOLOGICAL AND RADIOLOGICAL EVALUATION OF BENIGN BREAST DISEASES- A COMPARISON BETWEEN FNAC AND CORE BIOPSY
}

\author{
Saleem Tahir', Shariq Ahmad², R. C. Jain ${ }^{3}$ \\ ${ }^{1}$ Associate Professor, Department of Surgery, Era's Lucknow Medical College \& Hospital, Lucknow. \\ ${ }^{2}$ Senior Resident, Department of Surgery, Era's Lucknow Medical College \& Hospital, Lucknow. \\ 3Retired Professor, Department of Surgery, Era's Lucknow Medical College \& Hospital, Lucknow.
}

\begin{tabular}{l}
\hline ABSTRACT \\
BACKGROUND \\
Benign breast lumps are the most common lesions accounting for more than $90 \%$ of the cases presented. Fibroadenoma is a common \\
cause of benign breast lumps in premenopausal women. Fibrocystic disease of breast is a histological term referring to large group \\
of syndromes presenting as lumps or lumpiness. Follow-up studies have shown us that there is a relationship between benign breast \\
disease and breast cancer.
\end{tabular}

This study is aimed to exclude malignant breast condition and to emphasise their presentation and management.

\section{MATERIALS AND METHODS}

This study was conducted in Department of Surgery, ERA Medical College and Hospital, Lucknow in 50 subjects over a period of 1$1 / 2$ years. All patients presenting with palpable breast lump between 10-60 years of age were included in the study. The period of evaluation was from Oct. 2013 to May 2015. Clinicoradiological and pathological study of the various types of benign breast diseases has been done. Fibroadenoma formed the major component while fibrocystic diseases were few.

\section{RESULTS}

In the present study, 34 cases underwent excision of which 27 were of fibroadenoma and 6 were of fibroadenosis. All the patie nts with abscess underwent incision and drainage. There was a single case of duct ectasia who underwent microdochectomy. Lipoma, breast cyst all were excised. 5 cases of fibroadenosis underwent conservative management with medications which included reassurance, proper breast support, Tab. Evening Primrose Oil (EPO), Tab. Vitamin E, etc.

\section{CONCLUSION}

Surgical excision was an effective treatment for most of the benign breast diseases. Other modalities of treatment included Incision and drainage, microdochectomy \& aspiration. Sensitivity of clinical diagnosis to identify fibroadenoma was $85 \%$ and for fibroadenosis was $75 \%$. Sensitivity of FNAC for diagnosing fibroadenoma was $85 \%$ and for fibroadenosis was $82 \%$. Sensitivity of core biopsy was $92 \%$ for fibroadenoma and $83 \%$ for fibroadenosis.

\section{KEYWORDS}

Benign Breast Diseases, FNAC and Core Biopsy.

HOW TO CITE THIS ARTICLE: Tahir S, Ahmad S, Jain RC. Clinicopathological and radiological evaluation of benign breast diseases A comparison between FNAC and core biopsy. J. Evolution Med. Dent. Sci. 2016;5(94):6936-6939, DOI: 10.14260/jemds/2016/1570

\section{BACKGROUND}

Benign breast lumps are the most common lesions accounting for more than $90 \%$ of the cases presented, related to breast. 1 Fibroadenoma is a common cause of benign breast lumps in premenopausal women. Fibrocystic disease of breast is a histological term referring to large group of syndromes presenting as lump or lumpiness. Fibroadenomas are the most common cause of benign breast lumps. They usually present as solitary, firm, rubbery and non-tender lumps. Follow-up

Financial or Other, Competing Interest: None.

Submission 20-10-2016, Peer Review 13-11-2016,

Acceptance 19-11-2016, Published 24-11-2016.

Corresponding Author:

Dr. Saleem Tahir,

Associate Professor

Department of Surgery,

Era's Lucknow Medical College \&

Hospital, Sarfarazganj,

Lucknow-226003, Uttar Pradesh.

E-mail:dr_tahir75@yahoo.com

DOI: $10.14260 /$ jemds $/ 2016 / 1570$ studies have shown us that there is a relationship between benign breast disease and breast cancer. Risk of cancer varies according to the histological grading of benign breast disease.2,3,4,5. Thus, the aim of this study is to exclude malignant breast condition and to emphasise on their presentation, investigations and treatment of benign breast diseases.

This study of benign breast diseases includes 50 cases, where all possible attempts to study the various aspects of the disease, its presentation, investigations and management have been made. Evaluation of breast lumps in young females is essential to identify patients with benign proliferative lesions of the breast. Transition from normal to cancer begins by proliferation, then progresses to atypia \& finally arrives at neoplasia. ${ }^{6} \mathrm{~A}$ benign proliferative lesion of the breast is an important risk factor for subsequent transformation to malignancy. Karyotype \& molecular alteration in benign proliferative breast lesions parallel to those of breast carcinoma is noted. ${ }^{7}$ Proliferative lesions if recognised in the young population at an early stage along with a close followup \& careful watch would make it possible to abort the development of invasive cancer. ${ }^{8}$ 
The likely Cases to be Identified during the Study should Encompass

- Cysts.

- Fibroadenomas.

- Prominent Fat Lobules.

- $\quad$ Lymph Nodes.

- Haematomas.

- Hamartomas.

- Traumatic Fat Necrosis.

- Galactocoeles, etc.

Ultrasonography can effectively distinguish solid masses from cysts, which account for approximately 25 percent of breast. lesions. When strict criteria for cyst diagnosis are met, ultrasonography has a sensitivity of 89 percent and a specificity of 78 percent in detecting abnormalities in symptomatic women. Recurrent or complex cysts may signal malignancy; therefore, further evaluation of these lesions is required. FNAC breast is generally considered as a rapid, reliable, and safe diagnostic tool to distinguish non-neoplastic from neoplastic breast lesions. In developed countries, in the last 20 years, mammographic scoring programs, which have been used extensively, are designed to detect the earliest possible breast cancer. Core-needle biopsy (CNB) is increasingly replacing FNAC in many centres in developed countries and this is mainly attributed to the inability of FNAC to distinguish carcinoma in situ from invasive carcinoma. FNAC has a role in diagnosis of palpable breast lesions in developing countries as the initial method of pathological assessment. Also, as found by different authors like Zagorianaku et al and Koss et al, FNAC of palpable breast lesions is a component of Triple test. Also, factors like low cost, rapid reporting and patient compliance are better for FNAC procedure, even though it has limitations such as operator efficiency and the need of experienced medical staff. Epithelial hyperplasia, a component of proliferative breast disease (PBD), is a known risk factor for the development of breast carcinoma. The risk of breast carcinoma in cases of PBD without atypia is 1.3 times and in PBD with atypia is 4.3 times. Histological diagnosis is ultimate for confirmation. The present series will encompass both types of biopsies i.e. FNAC and core needle in randomised control way and then comparison will be done.

\section{MATERIALS AND METHODS}

This study was conducted in Postgraduate Department of Surgery, ERA Medical College and Hospital, Lucknow in 50 subjects over a period of $1-1 / 2$ years with following criteria and required materials and methods.

\section{Inclusion Criteria}

1. All patients presenting with palpable breast lump in surgical OPD or patients referred from other departments for same.

2. Age $>10-60$ years.

3. Breast pain but no palpable lumps were also included in the study. Identification of all patients were established by their name, age in years, sex, occupation, marital status. The clinical history will be based on presenting complaints, past history, family history, with special reference to presence of any breast disease in first degree relative, $\mathrm{OB} / \mathrm{GYN}$ history with special reference to parity, HRT, contraception and socioeconomic status.

\section{Criteria of Exclusion}

1. Male patients.

2. Already diagnosed cases of malignant breast disease elsewhere.

3. Secondaries in breast with primary elsewhere.

4. Previously operated for breast lump/carcinoma.

\section{Sample Size}

Calculated using formula.

$\mathrm{n}=(\mathrm{k}-1)\left\{\mathrm{z}^{2}(\mathrm{p} 1-\mathrm{p} 2)^{2}\right.$

$\mathrm{p} 1=0.67$

$\mathrm{p} 2=0.013$

$\mathrm{p}=(\mathrm{p} 1+$

Type I error $\alpha=5 \%$

Type II error $\beta=20 \%$

Power of study $=90 \%$

Data Loss $10 \%$

Minimal Sample Size Comes Out n=70

\begin{tabular}{|c|c|c|}
\hline Type & No. of Cases & Percentage \\
\hline Fibroadenoma & 27 & 54.0 \\
\hline Fibrocystic disease & 11 & 22.0 \\
\hline Abscess & 5 & 10.0 \\
\hline $\begin{array}{c}\text { Cyclical Mastalgia/ } \\
\text { Mastitis }\end{array}$ & 4 & 8.0 \\
\hline Galactocoele & 1 & 2.0 \\
\hline Duct Ectasia & 1 & 2.0 \\
\hline Benign Breast Cyst & 1 & 2.0 \\
\hline Total & 50 & 100 \\
\hline \multicolumn{3}{|c|}{$\begin{array}{l}\text { Benign Breast Diseases in the Present } \\
\text { series Diagnosed by Various Modalities }\end{array}$} \\
\hline
\end{tabular}

\begin{tabular}{|c|c|c|c|c|c|c|}
\hline Type & \multicolumn{7}{|c|}{ Age } & Total\% \\
\hline & $\mathbf{1 0 - 2 0}$ & $\mathbf{2 1 - 3 0}$ & $\mathbf{3 1 - 4 0}$ & $\mathbf{4 1 - 5 0}$ & $\mathbf{> 5 0}$ & \\
\hline Fibroadenoma & 1 & 17 & 9 & & & 55.0 \\
\hline Fibroadenosis & 1 & 6 & 4 & & & 22.0 \\
\hline Abscess & 3 & 2 & & & & 10.0 \\
\hline Cyclical mastalgia & 2 & 2 & & & & 8.0 \\
\hline Galactocoele & 1 & & & & & 2.0 \\
\hline Duct ectasia & 1 & & & & & 1.0 \\
\hline Benign cyst & & 1 & & & & 1.0 \\
\hline Total & $\mathbf{2}$ & $\mathbf{3 0}$ & $\mathbf{1 8}$ & & & $\mathbf{1 0 0}$ \\
\hline \multicolumn{7}{|c|}{ Age-wise Distribution of Various } \\
Benign Breast Disorders \\
\hline
\end{tabular}

In the present study, most common age at presentation is between 21 and 30 years and least common age at presentation is after 50 years of benign breast diseases.

Fibroadenoma was the commonest presentation in the age group of 21-30 and 31-40 years of age with 17 and 09 cases respectively. Fibroadenosis, cyclical mastalgia occurred commonly during 21-30 and 31-40 years range.

\section{Size of the Lesion}

The diameter of the lumps ranged from $<2 \mathrm{~cm}$ to $5 \mathrm{~cm}$ in 50 cases which were analysed in this study.

The smallest lesion was $1 \mathrm{sq} . \mathrm{cm}(1 \times 1 \mathrm{~cm})$ whereas the largest diagnosed was $8 \times 6 \mathrm{~cm}$.

37 patients had a lump of size between 2 and $5 \mathrm{~cm}$ of which 26 patients had fibroadenoma followed by 11 cases of fibroadenosis.

Most of the cases of lesion more than $5 \mathrm{~cm}$ were breast abscesses and only one case of giant fibroadenoma was recorded. 


\begin{tabular}{|c|c|c|c|c|}
\hline Disorders & $\begin{array}{c}\text { Clinical } \\
\text { Diagnosis }\end{array}$ & $\begin{array}{c}\text { Ultrasono- } \\
\text { graphy }\end{array}$ & Difference & $\begin{array}{c}\text { Sensiti- } \\
\text { vity }\end{array}$ \\
\hline Fibroadenoma & 10 & 9 & 1 & $90 \%$ \\
\hline Fibroadenosis & 6 & 6 & 0 & $100 \%$ \\
\hline Abscess & 2 & 2 & 0 & $100 \%$ \\
\hline Galactocoele & 2 & 2 & 0 & $100 \%$ \\
\hline Breast Cyst & 0 & 1 & 1 & $0 \%$ \\
\hline \multicolumn{6}{|c|}{ Total } & $\mathbf{2 0}$ & $\mathbf{2 0}$ & $\mathbf{3}$ & \\
\hline \multicolumn{4}{|c|}{ Comparative Correlation of Clinical and USG Finding } \\
\hline
\end{tabular}

In the present study, USG was done in 20 cases out of which 6 out of 8 clinically diagnosed fibroadenoma were diagnosed by USG with $90 \%$ sensitivity. Remaining 1 case was of fibroadenosis.

Cases of cysts, abscesses and galactocoele were more accurately diagnosed with USG.

\begin{tabular}{|c|c|c|c|c|}
\hline Disorders & $\begin{array}{c}\text { Clinical } \\
\text { Diagnosis }\end{array}$ & $\begin{array}{c}\text { HPE } \\
\text { Confirmation }\end{array}$ & Difference & $\begin{array}{c}\text { Sensitivity } \\
\text { of } \\
\text { Clinical } \\
\text { Diagnosis }\end{array}$ \\
\hline Fibroadenoma & 27 & 23 & 4 & $85.1 \%$ \\
\hline Fibroadenosis & 8 & 6 & 2 & $75 \%$ \\
\hline Breast cyst & 0 & 1 & 1 & $0 \%$ \\
\hline Lipoma & 0 & 1 & 1 & $0 \%$ \\
\hline Duct ectasia & 1 & 1 & 0 & $100 \%$ \\
\hline Total & $\mathbf{3 6}$ & $\mathbf{3 2}$ & $\mathbf{8}$ & \\
\hline \multicolumn{6}{|c|}{$\begin{array}{r}\text { Comparative Correlation of Clinical Diagnosis } \\
\text { with Histopathological Confirmation }\end{array}$} \\
\hline
\end{tabular}

In the present study, 27 cases were diagnosed as fibroadenoma clinically and underwent excision and histopathological study out of which 4 cases turned out to be of different diagnosis.

Of which most of them were fibroadenosis, one case turned out to be lipoma and one case turned out to be a benign breast cyst. Thus, the sensitivity of clinical diagnosis was $85 \%$ for clinical diagnosis.

Out of 8 cases of fibroadenosis who underwent excision, 2 cases turned out to be fibroadenoma on histopathological diagnosis. Thus, the sensitivity of clinical diagnosis for diagnosing fibroadenosis was $75 \%$. Duct ectasia and antibioma were diagnosed correctly by clinical methods and were confirmed by histopathology after excision.

\begin{tabular}{|c|c|c|c|c|}
\hline Disorders & FNAC & $\begin{array}{c}\text { HPE } \\
\text { Confirma- } \\
\text { tion }\end{array}$ & $\begin{array}{c}\text { Difference } \\
\text { in } \\
\text { Final } \\
\text { Diagnosis }\end{array}$ & $\begin{array}{c}\text { Sensitivity } \\
\text { of } \\
\text { FNAC }\end{array}$ \\
\hline Fibroadenoma & 17 & 15 & 2 & $88.2 \%$ \\
\hline Fibroadenosis & 08 & 06 & 2 & $75 \%$ \\
\hline Duct ectasia & 01 & 1 & 0 & $100 \%$ \\
\hline Breast cyst & 01 & 1 & 0 & $100 \%$ \\
\hline Lipoma & 01 & 1 & 1 & $100 \%$ \\
\hline Total & $\mathbf{2 8}$ & $\mathbf{2 4}$ & $\mathbf{5}$ & \\
\hline \multicolumn{5}{|c|}{$\begin{array}{c}\text { Comparative Correlation of FNAC } \\
\text { with Histopathological Confirmation }\end{array}$} \\
\hline \multicolumn{6}{|c|}{}
\end{tabular}

In the present study, 17 cases of fibroadenoma diagnosed on FNAC underwent excision and out of which 2 cases turned out to be fibroadenosis. Thus, the sensitivity of FNAC for fibroadenoma in the study was $88 \% .6$ cases of fibroadenosis diagnosed by FNAC underwent excision and 2 cases turned out to be fibroadenomas. Thus, the sensitivity of FNAC to diagnose fibroadenosis was $75 \%$.

\begin{tabular}{|c|c|c|c|c|}
\hline Disorders & $\begin{array}{c}\text { Core } \\
\text { Biopsy }\end{array}$ & $\begin{array}{c}\text { HPE } \\
\text { Confirma- } \\
\text { tion }\end{array}$ & $\begin{array}{c}\text { Difference } \\
\text { in } \\
\text { Final } \\
\text { Diagnosis }\end{array}$ & $\begin{array}{c}\text { Sensitivity } \\
\text { Core } \\
\text { Biopsy }\end{array}$ \\
\hline Fibroadenoma & 15 & 14 & 1 & $92 \%$ \\
\hline Fibroadenosis & 06 & 05 & 1 & $83 \%$ \\
\hline Duct Ectasia & 01 & 1 & 0 & $100 \%$ \\
\hline Breast Cyst & 01 & 1 & 0 & $100 \%$ \\
\hline Lipoma & 01 & 1 & 1 & $100 \%$ \\
\hline Total & $\mathbf{2 4}$ & $\mathbf{2 2}$ & $\mathbf{3}$ & \\
\hline \multicolumn{6}{|c|}{ Comparative Correlation of Core Biopsy with } \\
Histopathological Confirmation \\
\hline
\end{tabular}

Core biopsy was done in 15 patients and HPE confirmation received in 14 with sensitivity of $92 \%$. Similarly, in fibroadenosis, 6 cases were done and 1 case was of fibroadenoma with sensitivity of $83 \%$

\begin{tabular}{|c|c|c|c|c|c|c|}
\hline \multicolumn{7}{|c|}{ Treatment Modalities } \\
\hline Type & Excision & $\begin{array}{c}\text { Conser- } \\
\text { vative }\end{array}$ & I\&D & $\begin{array}{c}\text { Aspira- } \\
\text { tion }\end{array}$ & $\begin{array}{l}\text { Micro- } \\
\text { dochec- } \\
\text { tomy }\end{array}$ & Total \\
\hline $\begin{array}{c}\text { Fibro- } \\
\text { adenoma }\end{array}$ & 27 & 0 & 0 & 0 & 0 & 27 \\
\hline $\begin{array}{c}\text { Fibro- } \\
\text { adenosis }\end{array}$ & 06 & 05 & 0 & 0 & 0 & 11 \\
\hline Abscess & & 5 & & & 05 & \\
\hline Mastalgia & 04 & & & & 04 & \\
\hline Galactocoele & & 2 & & & 02 & \\
\hline Duct Ectasia & & & 1 & & 01 & \\
\hline $\begin{array}{c}\text { Lipoma } \\
\text { Benign Breast } \\
\text { Cyst }\end{array}$ & 01 & & & & & \\
\hline Total & 34 & 09 & 5 & 2 & 1 & 50 \\
\hline
\end{tabular}

\section{RESULTS}

Final diagnosis based on clinical, FNAC, USG, core biopsy and histopathology was established as fibroadenoma in 2 cases, fibroadenosis in 6 cases, breast abscess in 3 cases and galactocoele, lipoma, breast cyst and ectasia 1 case each.

On clinical evaluation, total of 35 cases were labelled as fibroadenoma and fibroadenosis while remaining were abscess, cyst, lipoma and ectasia, FNAC was performed in 28 cases, of these 26 were diagnosed as benign while 1 each as ectasia, cyst and lipoma.

Core biopsy was done in 24 cases, of these 21 were benign, remaining were cyst, ectasia, lipoma 1 each. On final diagnosis, 27 cases were of fibroadenoma, 6 of fibroadenosis, 1 lipoma, 5 of breast abscess, 2 of galactocoele, 1 ectasia and 1 cyst. Among clinical, FNAC and USG; FNAC was most accurate and USG least. An agreement of $92.2 \%$ was observed between core biopsy and FNAC. With respect to disagreement, 1 case diagnosed as fibroadenosis by core biopsy was diagnosed normal in FNAC, and 1 case diagnosed as fibroadenoma was confirmed as cyst on histopathology. 


\section{DISCUSSION}

Benign breast lesions hold a significance from a point of view that they have a potential to turn into malignancy. In view of the prognostic risk of their conversion into malignancy, it requires great precision and accuracy for their diagnosis. Mammography is a highly sensitive tool but lacks specificity. Other imaging such as CT tomography, H NMR spectroscopy is very costly and not $100 \%$ accurate.

The primary objective of treating surgeon is to reduce the extent of large incisions while at the same time obtain adequate specimen for accurate diagnosis. FNAC and core biopsy are two such modalities which work as a replacement for histopathology. Hence, the present study was planned to compare FNAC with Core Biopsy.

For this purpose, 50 histopathologically proven patients of benign breast disease were enrolled in this study and were subjected to a thorough demographic, clinical, haematological, biochemical, radiological and pathological evaluation. In the present study, core biopsy had $92 \%$ sensitivity and $100 \%$ specificity whereas FNAC had sensitivity of $85 \%$ and specificity of $98.6 \%$. In the present study, we tried to segregate fibroadenoma/fibroadenosis from other diagnosis. Fibroadenoma and fibroadenosis are basically marked by cytological changes which are more clearly visible in FNAC as well as core biopsy examination. In the past, focus of FNAC and $\mathrm{CB}$ has generally been in differentiating benign from malignant diseases; however, the present study found them to be equally useful in differential diagnosis of benign breast diseases. Given the varying prognostic significance of different benign breast diseases, these two least invasive techniques are helpful in the prognosis, treatment and management without essential requirement of histopathology. Further studies to corroborate the findings of the present study are recommended.

\section{Summary}

In this study, 50 cases of benign breast diseases were evaluated during the period of Oct. 2013 to May 2015. Clinicoradiological and pathological study of the various types of benign breast disease has been done. In my study, fibroadenoma formed the major component forming 54\% of cases followed by fibrocystic diseases in $22 \%$ cases. Puerperal breast abscess comprised 4 cases, cyclical mastalgia 3 cases, galactocoele 1 case, and benign breast cyst, lipoma and duct ectasia accounted for 1 case each. High resolution USG was done in 20 patients in those where clinical diagnosis has not been confirmed, out of which 9 were of fibroadenoma and 6 were fibroadenosis. Conservative management (Reassurance, breast support, evening primrose oil, vitamin E, danazol, etc.) was done in all patients of cyclical mastalgia (4) and in patients with fibroadenosis (5).

Surgical excision was an effective treatment for most of the benign breast diseases (35 cases). Other modalities of treatment included Incision and Drainage (I\&D), microdochectomy, aspiration. 5 patients with fibroadenosis failed on conservative management and required excision. Sensitivity of clinical diagnosis to identify fibroadenoma was $85 \%$ and for fibroadenosis was $75 \%$. Sensitivity of FNAC for diagnosing fibroadenoma was $85 \%$ and for fibroadenosis was $82 \%$. Sensitivity of core biopsy was $92 \%$ for fibroadenoma and $83 \%$ for fibroadenosis.

In view of the above summary of work, the following conclusions can be drawn in our series.

\section{CONCLUSION}

1. Majority of the benign breast diseases occur in younger age group.

2. Most common presenting complaints are lump in the breast, pain in the breast, followed by nipple discharge.

3. Fibroadenoma and fibroadenosis are the most common benign breast diseases.

4. Early onset of fibroadenoma and fibrocystic diseases is attributed to early menarche.

5. Majority of lumps are noticed accidentally by the patient.

6. Majority of breast lumps are painless to present with.

7. Fibroadenoma usually present with unilateral solitary lump but multiple fibroadenomas in single breast and fibroadenomas in both breasts may also be present.

8. Diseases like ductal ectasia, lipoma and antibioma are extremely rare.

9. High resolution ultrasonography (HRUSG) is very useful in diagnosing abscess, cysts and galactocoele.

10. Fine needle aspiration cytology (FNAC) is a sensitive \& simple cost effective investigation in benign breast disease, but the sensitivity of core biopsy is more accurate.

\section{REFERENCES}

1. Ortiz MB, Hernandez BD, Mateos RC, et al. Benign breast diseases: clinical, radiological and pathological correlation. Gynecology Obstretics Mexican 2002;70:6138.

2. Wang J, Costantino JP, Tan-Chiu E, et al. Lower category benign breast disease and the risk of invasive breast cancer. Journal National Cancer Institute 2004;96(8):61620.

3. Schnitt SJ. Benign breast disease and breast cancer risk: morphology and beyond. American Journal of Surgical Pathology 2003;27(6):836-41.

4. Hill DA, Preston-Martin S, Ross RK, et al. Medical radiation, family history of cancer and benign breast disease in relation to breast cancer risk in young women, in U.S.A. Cancer Causes Control 2002;13(8):711-8.

5. Webb PM, Byrne C, Schnitt SJ, et al. Family history of breast cancer, age and benign breast disease. Int J Cancer 2002;100(3):375-8.

6. Gump FE. Premalignant diseases of breast. Surg Clin North Am 1984;64(6):1051-9.

7. Micale MA, Visscher DW, Gulino SE, et al. Chromosomal aneuploidy in proliferative breast disease. Hum Pathology 1994;25(1):29-35.

8. Malik R, Bharadwaj VK. Breast lesions in young females-a 20 year study for significance of early recondition. Indian J Pathol Microbiol 2003;46(4):559-62. 